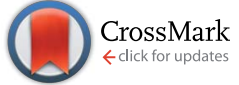

Cite this: RSC Adv., 2016, 6, 37031

Received 7th February 2016

Accepted 1st April 2016

DOI: 10.1039/c6ra03551e

www.rsc.org/advances

\section{An efficient and green method for regio- and chemo-selective Friedel-Crafts acylations using a deep eutectic solvent ([CholineCl] $\left.\left[\mathrm{ZnCl}_{2}\right]_{3}\right) \dagger$}

\begin{abstract}
Phuong Hoang Tran, ${ }^{a}$ Hai Truong Nguyen, ${ }^{a}$ Poul Erik Hansen ${ }^{b}$ and Thach Ngoc Le ${ }^{\star a}$
[Choline $\mathrm{Cl}]\left[\mathrm{ZnCl}_{2}\right]_{3}$, a deep eutectic solvent between choline chloride and $\mathrm{ZnCl}_{2}$, has been used as a dual function catalyst and green solvent for the Friedel-Crafts acylation of aromatic compounds instead of using the moisture-sensitive Lewis acids and volatile organic solvents. The reactions are performed with high yields under microwave irradiation with short reaction times for the synthesis of ketones. Interestingly, indole derivatives are regioselectively acylated in the 3-position under mild conditions with high yields without $\mathrm{NH}$ protection. Three new ketone products are synthesized. [CholineCl] $\left[\mathrm{ZnCl}_{2}\right]_{3}$ is easily synthesized from choline chloride and zinc chloride at a low cost, with easy purification and environmentally benign compounds. [CholineCl] $\left[\mathrm{ZnCl}_{2}\right]_{3}$ can be reused up to five times without loss of catalytic activity, making it ideal in industrial processes.
\end{abstract}

\section{Introduction}

The Friedel-Crafts acylation is an important tool for organic syntheses of aromatic ketones, which are useful precursors in the synthesis of pharmaceuticals, agrochemicals, dyes and fragrances. ${ }^{1-6}$ The traditional Lewis acids catalyzing FriedelCrafts acylations are always used in more than stoichiometric amounts, and cannot be recovered and reused after aqueous workup. $^{2,7}$ Thus, traditional Lewis acids are not useful in industrial processes due to environmental problems. Consequently, there is considerable interest in the development of green catalysts and efficient methods for regio- and chemoselectivity in the Friedel-Crafts acylation. ${ }^{8-15}$ Over the past decade there has been an explosion in the development of green catalysts for Friedel-Crafts acylation, and a large number of papers have been published. ${ }^{7,16-20}$ Among these catalysts, ionic liquids have attracted increasing interest as solvents because of their unique chemical and physical properties, such as low or non-volatility, thermal stability and large liquid range. ${ }^{21-23}$ Consequently, ionic liquids gain a special attraction as green solvents to replace volatile organic solvents. ${ }^{24}$

The Friedel-Crafts acylation using ionic liquids as green solvents aims to increase the yield and to recycle the catalytic system without significant loss of the catalytic activity. ${ }^{23}$ The

\footnotetext{
${ }^{a}$ Department of Organic Chemistry, Faculty of Chemistry, University of Sciences, Vietnam National University, Ho Chi Minh City 70000, Vietnam. E-mail: lenthach@ yahoo.com; thphuong@hcmus.edu.vn

${ }^{b}$ Department of Science, Systems and Models, Roskilde University, DK-4000 Roskilde, Denmark

$\dagger$ Electronic supplementary information (ESI) available. See DOI: 10.1039/c6ra03551e
}

catalytic systems containing the catalyst and ionic liquids are dried under vacuum for a period of from one to three hours before being used in the next cycle. ${ }^{23}$ Various homogeneous and heterogeneous catalysts dissolved in ionic liquids gave the best conversion. ${ }^{24}$ However, high cost, environmental toxicity and high purity requirement limit the use of ionic liquids in organic synthesis. ${ }^{23}$ Recently, the first integrated ionic liquids have been easily prepared in high purity ${ }^{25-27}$ such as chloroaluminate ionic liquid, which was reported as an efficient catalyst for Friedel-Crafts acylation, but its poor stability to moisture generated undesired products necessitating the use of an inert atmosphere. ${ }^{28-31}$ In addition, the recovery and reuse of the first integrated ionic liquids led to decrease of reaction yields due to the loss of metal chloride into the product stream as benzophenone-metal chloride adduct. ${ }^{29}$ In addition, gradual decomposition of the catalyst is also an environmental problem. ${ }^{32}$

Recently, Abbott and co-workers have promoted and developed a new class of ionic liquids called deep eutectic solvents (DES) which are often composed of choline chloride and one or two other components. ${ }^{33}$ Generally, DES are easily formed through hydrogen bond interaction, resulting in a lower melting point than those of the individual components. ${ }^{34,35} \mathrm{~A}$ slightly different type of DES is formed between choline chloride and zinc chloride, which can be used as stable Lewis acids and green solvents for organic syntheses and electrochemical applications. ${ }^{36}$ The advantages of DES are easy synthesis with high purity, non-toxicity, biodegradability and lower price than traditional ionic liquids. ${ }^{35,37-39}$

In this paper, we report a green and efficient method with high regio- and chemoselective Friedel-Crafts acylation using acid anhydrides and $[\mathrm{CholineCl}]\left[\mathrm{ZnCl}_{2}\right]_{3}$ as catalyst under 
microwave irradiation. A deep eutectic solvent was used as catalyst for many organic transformations. ${ }^{40-48}$ In particular, DES was used as Lewis acid catalyst in Friedel-Crafts alkylation including alkenylation/alkylation of indole with 1,3-dicarbonyl compounds, ${ }^{49}$ alkylation of indoles, ${ }^{50}$ alkylation of electron-rich arenes with aldehyde ${ }^{51}$ and alkylation of thiophenic compounds. ${ }^{52}$ However its use as a catalyst for Friedel-Crafts acylation reactions remains unreported. This is the first application, to our knowledge, of $[\mathrm{CholineCl}]\left[\mathrm{ZnCl}_{2}\right]_{3}$ as a catalyst for Friedel-Crafts acylation reactions. The $[$ CholineCl $]\left[\mathrm{ZnCl}_{2}\right]_{3}$ used in this work had a melting point of $45^{\circ} \mathrm{C} .{ }^{36}$ Choline chloride and zinc chloride are both inexpensive and the processes of using deep eutectic solvents like $[\mathrm{CholineCl}]\left[\mathrm{ZnCl}_{2}\right]_{3}$ can be easily applied in industry.

\section{Results and discussion}

[CholineCl $]\left[\mathrm{ZnCl}_{2}\right]_{3}$ was easily prepared by heating and stirring a mixture of choline chloride $(20 \mathrm{mmol})$ and zinc chloride (60 $\mathrm{mmol})$ at $100{ }^{\circ} \mathrm{C}$ until a clear, colorless liquid was obtained. ${ }^{36}$

First, our investigation focused on finding the optimal mixture of choline chloride and zinc chloride. The FriedelCrafts acylations of anisole and indole with propionic anhydride were tested under microwave (MW) irradiation at $120{ }^{\circ} \mathrm{C}$ for $5 \mathrm{~min}$ (see Table 1). The best conversions were obtained under microwave irradiation with high regio-selectivity when [CholineCl] $\left[\mathrm{ZnCl}_{2}\right]_{3}$ was used as the catalyst (Table 1 , entries 4 and 8). It could be explained by the stronger Lewis acidity with more zinc chloride used. [CholineCl] $\left[\mathrm{ZnCl}_{2}\right]_{3}$ was used in a less than stoichiometric amount ( $35 \mathrm{~mol} \%$ ) and was easily recovered and reused without significant loss of activity (see below).

Anisole was chosen as a model substrate, and [CholineCl]$\left[\mathrm{ZnCl}_{2}\right]_{3}$ catalyst was used to screen for the optimal condition under microwave irradiation at $100-140{ }^{\circ} \mathrm{C}$ for $5 \mathrm{~min}$. The results are summarized in Table 2 . Interestingly, all acid anhydrides, such as acetic anhydride, propionic anhydride, butyric anhydride, iso-butyric anhydride and benzoic anhydride, gave ketone products with major $p$-isomer and no demethylation products were observed. Surprisingly, pivalic anhydride was not reactive under the same reaction conditions (Table 2, entries 911). Anisole is acylated to afford the corresponding ketones in excellent yields at $120^{\circ} \mathrm{C}$ for 5 min under microwave irradiation. Among the tested acid anhydrides, propionic and benzoic anhydride provide the highest yields. The above mentioned

Table 2 Acylation scope with respect to acid anhydride ${ }^{a}$

\begin{tabular}{|c|c|c|c|c|}
\hline & $+(\mathrm{RCO}$ & ${ }_{2} \mathrm{O} \frac{\text { [CholineCl] }\left[\mathrm{ZnCl}_{2}\right.}{2}$ & $\underset{3 \mathrm{~min}}{\stackrel{3}{35 \mathrm{~mol} \%}}$ & $\begin{array}{l}\mathrm{Me} \\
+\mathrm{RCOOH}\end{array}$ \\
\hline Entry & $-\mathrm{R}$ & Temperature $\left({ }^{\circ} \mathrm{C}\right)$ & Conversion $^{b}(\%)$ & Selectivity $^{c}(\%)$ \\
\hline 1 & $\mathrm{CH}_{3}$ & 100 & 90 & $5 / 0 / 95$ \\
\hline 2 & & 120 & 95 & $5 / 0 / 95$ \\
\hline 3 & $\mathrm{C}_{2} \mathrm{H}_{5}$ & 100 & 87 & $3 / 0 / 97$ \\
\hline 4 & & 120 & 97 & $8 / 0 / 92$ \\
\hline 5 & $\mathrm{C}_{3} \mathrm{H}_{7}$ & 100 & 54 & $3 / 0 / 97$ \\
\hline 6 & & 120 & 86 & $2 / 0 / 98$ \\
\hline 7 & $\mathrm{i}-\mathrm{C}_{3} \mathrm{H}_{7}$ & 100 & 79 & $2 / 0 / 98$ \\
\hline 8 & & 120 & 93 & $3 / 0 / 97$ \\
\hline 9 & $t-\mathrm{C}_{4} \mathrm{H}_{9}$ & 100 & 0 & - \\
\hline 10 & & 120 & 0 & - \\
\hline 11 & & 140 & 0 & - \\
\hline 12 & $\mathrm{C}_{6} \mathrm{H}_{5}$ & 100 & 71 & $8 / 0 / 92$ \\
\hline 13 & & 120 & 97 & $0 / 0 / 100$ \\
\hline
\end{tabular}

a Anisole (1 mmol), acylating reagent $(1 \mathrm{mmol})$, [CholineCl] $\left[\mathrm{ZnCl}_{2}\right]_{3}$ $(0.35 \mathrm{mmol}) .{ }^{b}$ Conversion was reported by GC. ${ }^{c}$ The ratio of ortho/ meta/para isomers was determined by GC.

Table 1 Optimization of the ratio between choline chloride and zinc chloride

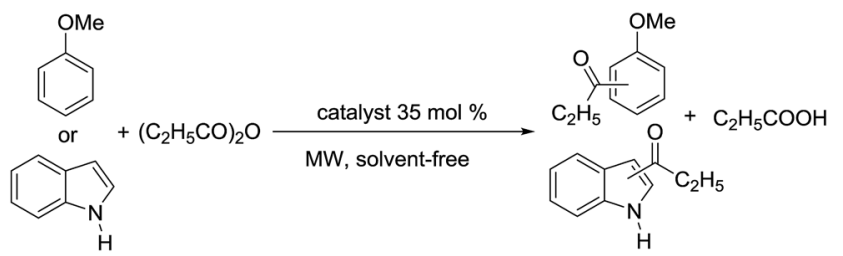

\begin{tabular}{|c|c|c|c|c|}
\hline Entry & Substrate & Catalyst & Conversion $^{c}(\%)$ & Selectivity ${ }^{c, d}(\%)$ \\
\hline 1 & Anisole $^{a}$ & $\mathrm{ZnCl}_{2}$ & 48 & $5 / 0 / 95$ \\
\hline 2 & & {$[$ CholineCl $]\left[\mathrm{ZnCl}_{2}\right]$} & 60 & $6 / 0 / 94$ \\
\hline 4 & & {$[$ CholineCl $]\left[\mathrm{ZnCl}_{2}\right]_{3}$} & 99 & $2 / 0 / 98$ \\
\hline 5 & Indole $^{b}$ & $\mathrm{ZnCl}_{2}$ & 63 & $4 / 0 / 96$ \\
\hline 6 & & {$[$ CholineCl $]\left[\mathrm{ZnCl}_{2}\right]$} & 66 & $4 / 0 / 96$ \\
\hline
\end{tabular}

${ }^{a}$ Anisole $(1 \mathrm{mmol})$, propionic anhydride $(1 \mathrm{mmol}), \mathrm{MW}\left(120^{\circ} \mathrm{C}, 5 \mathrm{~min}\right) \cdot{ }^{b}$ Indole $(1 \mathrm{mmol})$, propionic anhydride $(1 \mathrm{mmol}), \mathrm{MW}\left(120{ }^{\circ} \mathrm{C}, 10 \mathrm{~min}\right)$.

${ }^{c}$ Conversion and selectivity were determined by GC. ${ }^{d}$ Selectivity: anisole (ortho/meta/para isomers), indole (1/2/3 position). 
View Article Online

Paper

RSC Advances

Table 3 Friedel-Crafts acylation of various aromatic compounds and five-membered heterocycles ${ }^{a}$

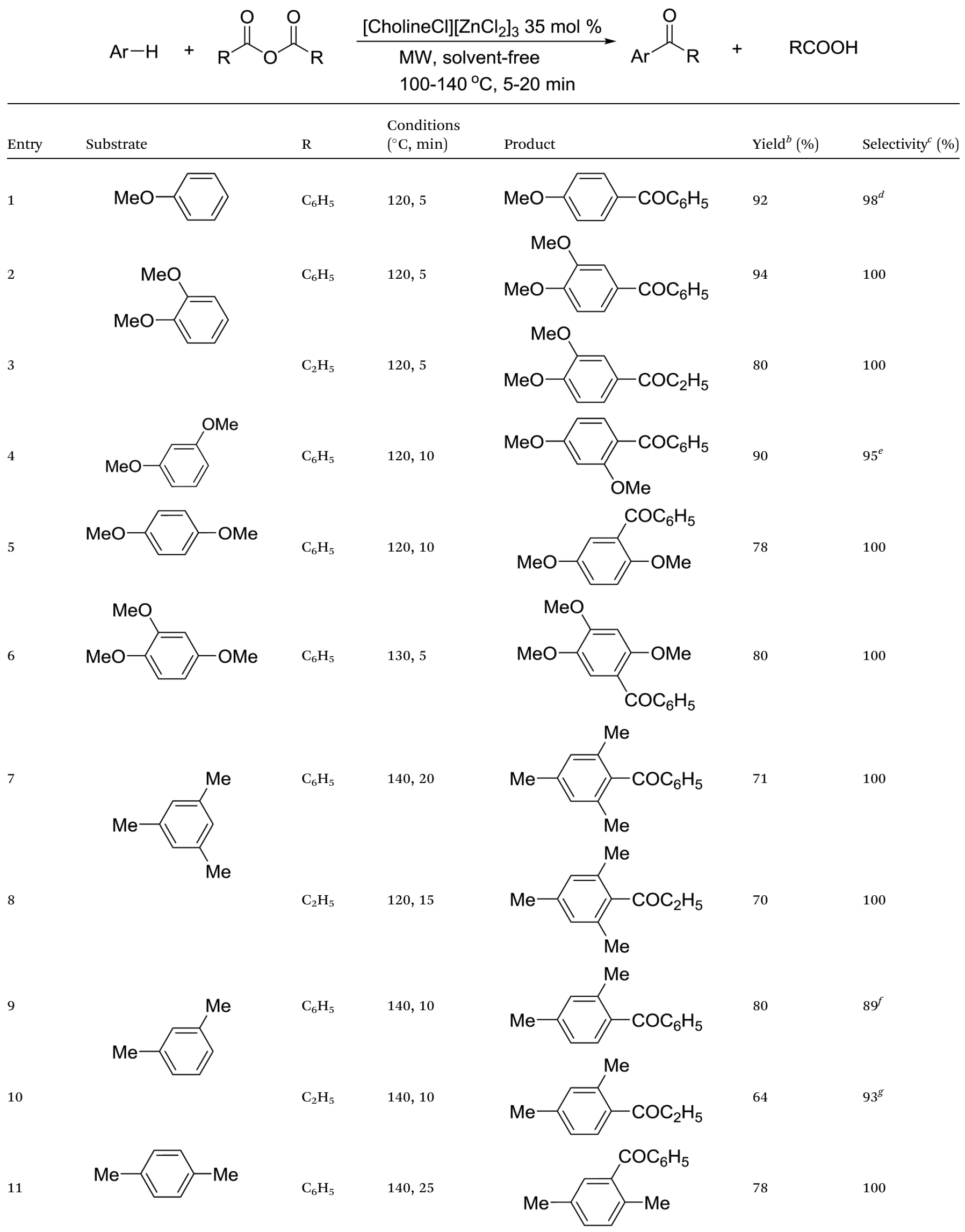


Table 3 (Contd.)

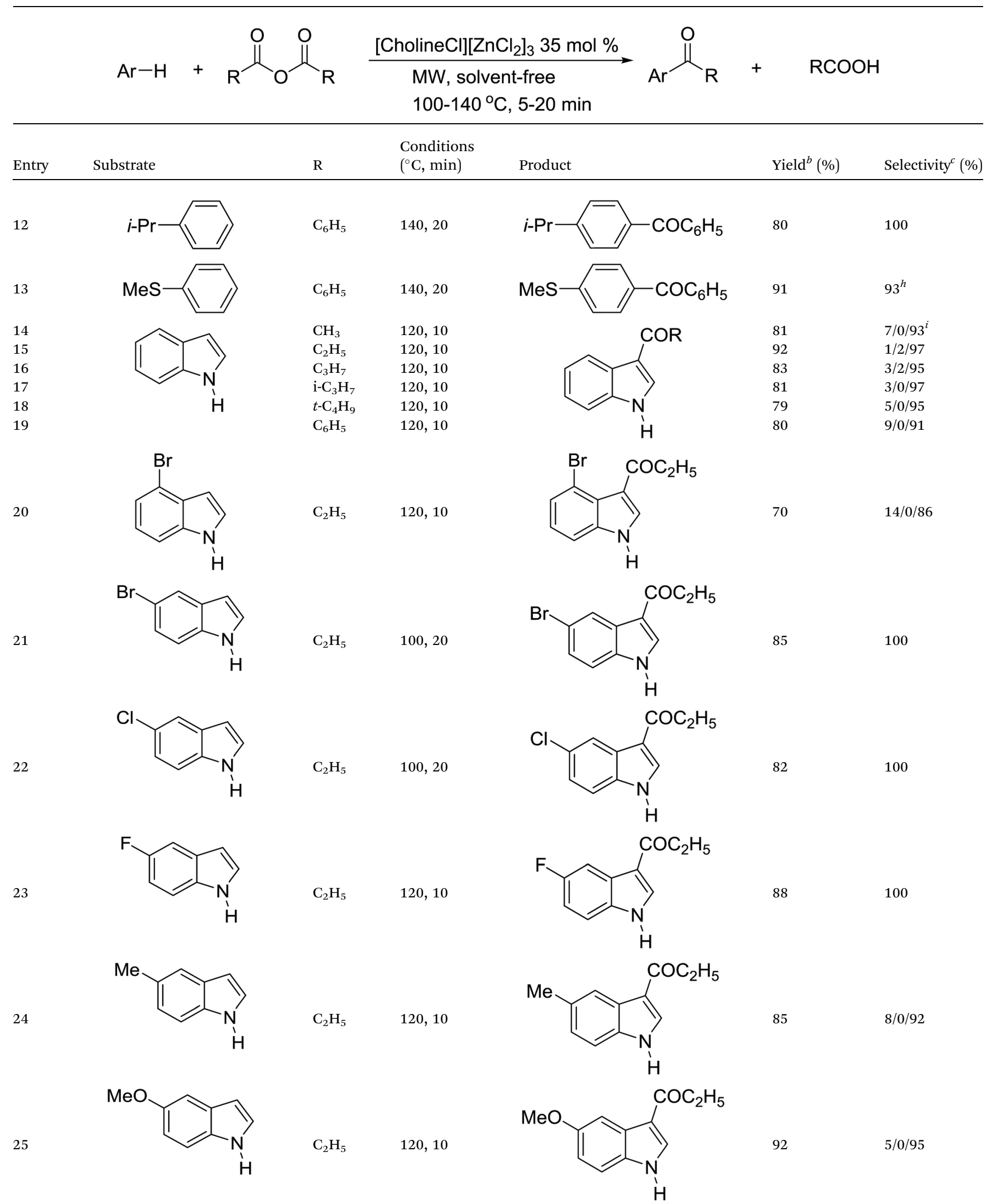




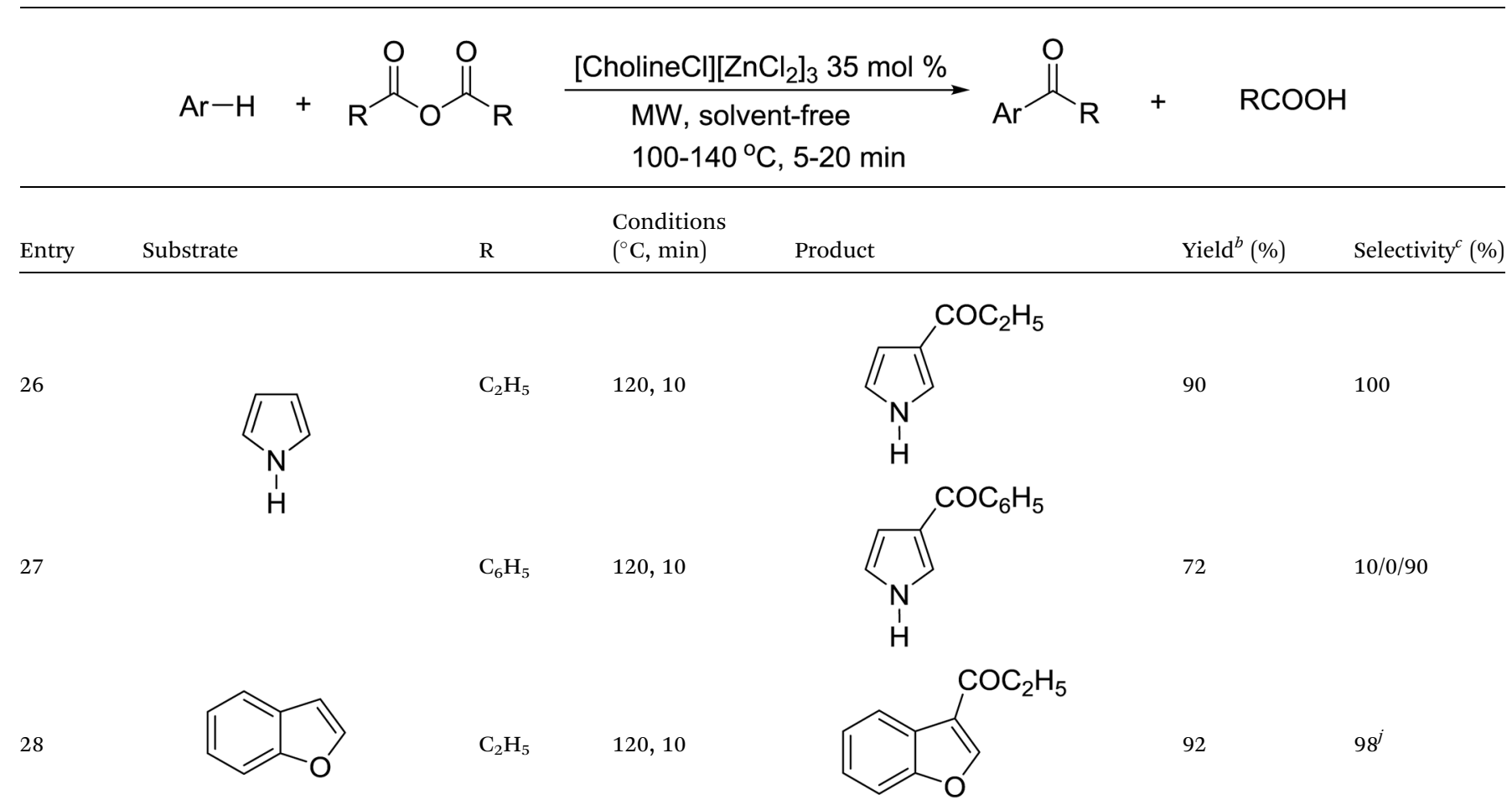

\footnotetext{
${ }^{a}$ Arene $(1 \mathrm{mmol})$, acylating reagent $(1 \mathrm{mmol})$, [CholineCl] $\left[\mathrm{ZnCl}_{2}\right]_{3}(0.35 \mathrm{mmol}){ }^{b}$ Yields are for the isolated, pure isomer. ${ }^{c}$ Selectivity is determined by GC. ${ }^{d}$ ortho/para $=2 / 98$. ${ }^{e} 2,6$-Dimethoxybenzophenone/2,4-dimethoxybenzophenone $=5 / 95$. ${ }^{f} 2,6$-Dimethylbenzophenone/2,4dimethylbenzophenone $=11 / 89 .{ }^{g}$ 2,6-Dimethylpropiophenone/2,4-dimethylpropiophenone $=7 / 93 .{ }^{h}$ ortho/para $=7 / 93$. ${ }^{i}$ For indoles and pyrrole the selectivity is given as 1-/2-/3- isomers. ${ }^{J}$ 1-(Benzofuran-2-yl)propan-1-one/1-(benzofuran-3-yl)propan-1-one $=2 / 98$.
}

conditions were applied to the Friedel-Crafts acylation of a variety of aromatic compounds as seen in Table 3.

The aromatic compounds with electron-donating (methoxy) substituents are reactive under optimized conditions, affording the benzoylated products in good to excellent yields (entries 1 , $2,4,5)$. No demethylation was observed in this method, with the exception of 1,2,4-trimethoxybenzene (less than 10\%). The Friedel-Crafts propionylation of veratrole gave a lower yield than benzoylation under similar conditions. Although alkylbenzenes were acylated in good yields (64-80\%), higher temperatures and longer reaction times were required than for methoxybenzene derivatives. Thioanisole was reactive under optimized conditions in excellent yield.

Indoles are important compounds used in many pharmaceuticals. Especially, the Friedel-Crafts acylation of indoles at position 3 has attracted much attention in the past decade. ${ }^{13,53-60}$ So far the use of DES as catalyst for this reaction has not, to our knowledge, been reported. In this paper, we report the Friedel-Crafts acylation of indoles at position 3 without $N$-protection.

Minor modification of the optimized conditions were made when the Friedel-Crafts acylation of indole with six types of acid anhydrides was investigated at $120{ }^{\circ} \mathrm{C}$ for $10 \mathrm{~min}$ under microwave irradiation. In most cases, the major product was the 3-substituted one $(>90 \%)$. The highest yield was obtained with propionic anhydride. Interestingly, pivalic anhydride, which is more sterically hindered than the others, was also reactive in this method, giving a product in $79 \%$ yield (entry 18 ).

Table 3 shows a variety of reactions in which the reactivity of indoles bearing electron-poor (halogens) or electron-rich substituents at position 5 was investigated. The halogencontaining indoles selectively afforded 3-propionylation products in good yields in spite of weakly deactivating substituents (entries 21-23). 4-Bromoindole was propionylated in $70 \%$ yield with $86 \%$ selectivity at position 3 due to the steric effect of the bromo substituent in the benzene ring. 5-Methylindole was propionylated in $85 \%$ yield (entry 24). 5-Methoxyindole, with electron-donating substituent (methoxy) making it more reactive, provided $92 \%$ yield (entry 25). Furthermore, a negligible quantity of $\mathrm{N}$-acylated products $(1-5 \%)$ were generated and no 1,3-diacylation or polymerization occurred in our method. Pyrrole and benzofuran also afforded 3-acylated products in excellent yields (entries 26-28).

The recovery and reuse of $[\mathrm{CholineCl}]\left[\mathrm{ZnCl}_{2}\right]_{3}$ is necessary for economic and environmental reasons. After extraction, $[$ CholineCl $]\left[\mathrm{ZnCl}_{2}\right]_{3}$ is dried under vacuum at $80{ }^{\circ} \mathrm{C}$ for one hour. Then the recycled [CholineCl] $\left[\mathrm{ZnCl}_{2}\right]_{3}$ is used in further Friedel-Crafts acylations (Scheme 1). Interestingly, the catalyst was stable after five consecutive cycles without significant loss of the activity. Hence, this result is useful for future industrial applications. 

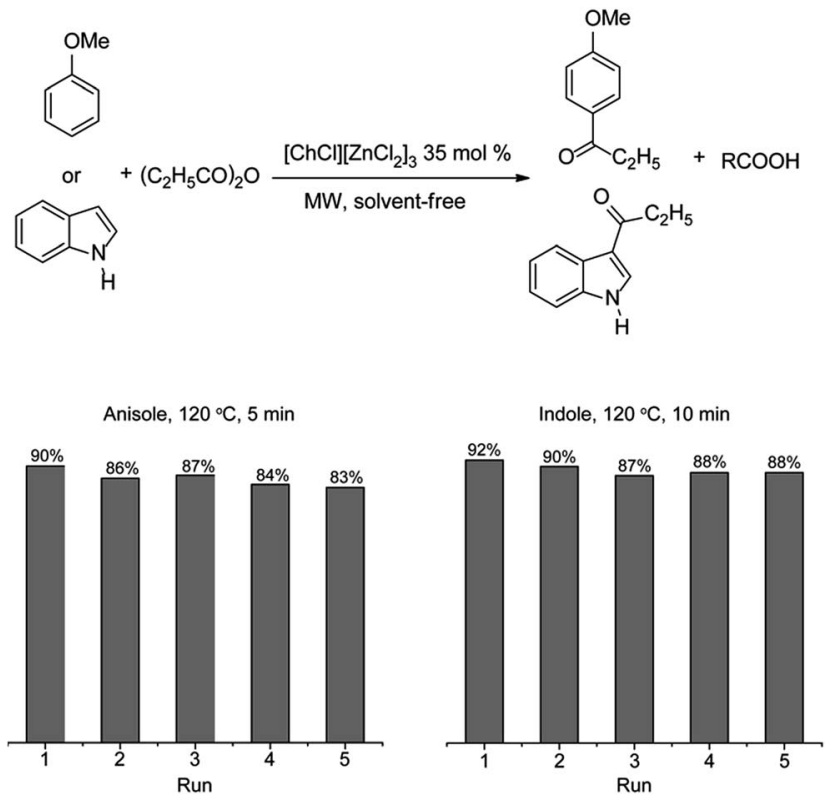

Scheme 1 Recycling of [CholineCl] $\left[\mathrm{ZnCl}_{2}\right]_{3}$.

\section{Experimental}

\section{Chemicals, supplies and instruments}

(2-Hydroxyethyl)trimethylammonium (choline chloride, purity $\geq 99.0 \%$ ) was obtained from HiMedia Laboratories Pvt. Ltd (India). Zinc chloride (purity $\geq 98 \%$ ) was obtained from SigmaAldrich. Anisole (analytical standard, GC, purity $\geq 99.9 \%$ ), indole (purity $\geq 99 \%$ ), propionic anhydride (purity $\geq 96 \%$ ), acetic anhydride (purity $\geq 99 \%$ ), butyric anhydride (purity $\geq$ $97 \%$ ), isobutyric anhydride (purity $\geq 99 \%$ ), $t$-butyric anhydride (purity $\geq 99 \%$ ), benzoic anhydride (purity $\geq 95 \%$ ), 1,2-dimethoxybenzene (purity $\geq 99 \%$ ), 1,3-dimethoxybenzene (purity > 98\%), 1,4-dimethoxybenzene (purity > 99\%), 1,2,4-trimethoxybenzene (purity $\geq 97 \%$ ), mesitylene (purity $\geq 99 \%$ ), $m$-xylene (purity $\geq 98 \%$ ), $p$-xylene (purity $\geq 99 \%$ ), cumene (purity $\geq$ $98 \%$ ), thioanisole (purity $\geq 99 \%$ ), 4-bromoindole (purity $\geq$ 96\%), 5-bromoindole (purity $\geq 99 \%$ ), 5-chloroindole (purity $\geq$ 98\%), 5-fluoroindole (purity $\geq 98 \%$ ), 5-methylindole (purity $\geq$ 98\%), 5-methoxyindole (purity $\geq 99 \%$ ), pyrrole (purity $\geq 98 \%$ ) and benzofuran (purity $\geq 99 \%$ ) were obtained from SigmaAdrich. Silica gel 230-400 mesh, for flash chromatography was obtained from HiMedia Laboratories Pvt. Ltd (India). TLC plates (silica gel 60 F254) were obtained from Merck. Ethyl acetate (purity $\geq 99.5 \%$ ), $n$-hexane and chloroform (purity $\geq$ 99\%) were obtained from Xilong Chemical Co., Ltd (China). Chloroform-d, 99.8 atom\% D, stabilized with Ag, was obtained from Armar (Switzerland).

All starting materials, reagents and solvents were used without further purification.

Microwave irradiation was performed on a CEM Discover BenchMate apparatus which offers microwave synthesis with safe pressure regulation using a $10 \mathrm{~mL}$ pressurized glass tube with Teflon-coated septum and vertically-focused IR temperature sensor controlling reaction temperature. Melting point was performed on a Büchi B-545. GC-MS analyses were performed on an Agilent GC System 7890 equipped with a mass selective detector (Agilent 5973N) and a capillary DB-5MS column (30 m $\times 250 \mu \mathrm{m} \times 0.25 \mu \mathrm{m})$. The ${ }^{1} \mathrm{H}$ and ${ }^{13} \mathrm{C}$ NMR spectra were recorded on Bruker Avance 500 and Varian Mercury 300 instruments using DMSO- $\mathrm{d}_{6}$ or $\mathrm{CDCl}_{3}$ as solvent and solvent peaks or TMS as internal standards. HRMS (ESI) data were recorded on a Bruker micrOTOF-QII MS at $80 \mathrm{eV}$.

\section{General procedure for Friedel-Crafts acylation}

A mixture of [CholineCl] $\left[\mathrm{ZnCl}_{2}\right]_{3}(0.192 \mathrm{~g}, 0.35 \mathrm{mmol})$, anisole $(0.108 \mathrm{~g}, 1 \mathrm{mmol})$ and benzoic anhydride $(0.226 \mathrm{~g}, 1 \mathrm{mmol})$ was heated under microwave irradiation at $120{ }^{\circ} \mathrm{C}$ for $5 \mathrm{~min}$ in a CEM Discover apparatus. After being cooled, the mixture was extracted with diethyl ether $(3 \times 15 \mathrm{~mL})$. The organic layer was decanted, washed with $\mathrm{H}_{2} \mathrm{O}(10 \mathrm{~mL})$, aqueous $\mathrm{NaHCO}_{3}(2 \times 20$ $\mathrm{mL})$, and brine $(10 \mathrm{~mL})$, and dried over $\mathrm{Na}_{2} \mathrm{SO}_{4}$. The solvent was removed on a rotary evaporator. The crude product was purified by flash chromatography ( $n$-hexane, then $10 \%$ ethyl acetate in $n$ hexane) to give 4-methoxybenzophenone ( $0.195 \mathrm{~g}, 92 \%$ yield). The purity and identity of the product were confirmed by GC-MS spectra which were compared with the spectra in the NIST library, and by ${ }^{1} \mathrm{H}$ and ${ }^{13} \mathrm{C}$ NMR spectroscopy.

\section{Recycling of [CholineCl] $\left[\mathrm{ZnCl}_{2}\right]_{3}$}

This procedure was also carried out in a monomode microwave oven, on indole and anisole. In order to recover the catalytic $[$ CholineCl $]\left[\mathrm{ZnCl}_{2}\right]_{3}$, after completion of the reaction, diethyl ether was applied to wash the reaction mixture as many times as necessary to completely remove both substrates and products. Then, the mixture containing $[\mathrm{CholineCl}]\left[\mathrm{ZnCl}_{2}\right]_{3}$ was dried in a vacuum at $80^{\circ} \mathrm{C}$ for $60 \mathrm{~min}$. This recycled system was used for four consecutive runs and it is worth noting that the isolated yield of the product decreased slightly after each run. The process for recycling [CholineCl] $\left[\mathrm{ZnCl}_{2}\right]_{3}$ is simple and efficient so it could be applied on a large scale.

\section{Conclusions}

We have developed a novel catalyst taking advantage of green and efficient catalytic activity under microwave irradiation. The use of $[\mathrm{CholineCl}]\left[\mathrm{ZnCl}_{2}\right]_{3}$ allows regioselective acylation of aromatic compounds and five-membered heterocycles under mild conditions. A variety of electron-rich compounds such as alkylbenzenes, anisole derivatives, and five-membered heterocycles are reactive using the present method. This catalyst possesses several advantages such as low toxicity, low cost, easy handling, and easy recycling. The procedure is simple, good to excellent yields are obtained, and further potential applications can be foreseen.

\section{Acknowledgements}

This research is funded by Vietnam National University-Ho Chi Minh City (VNU - HCM) under grant number C2016-18-21. We thank Duy-Khiem Nguyen Chau (University of Minnesota - 
Duluth, USA) and Ngoc-Mai Hoang Do (IPH-HCM) for their valuable discussions.

\section{References}

1 G. A. Olah, Friedel-Crafts Chemistry, John Wiley and Sons, New York, 1973.

2 S. P. Chavan, S. Garai, A. K. Dutta and S. Pal, Eur. J. Org. Chem., 2012, 6841-6845.

3 I. T. Chen, I. Baitinger, L. Schreyer and D. Trauner, Org. Lett., 2014, 16, 166-169.

4 K. Chen, C. Risatti, M. Bultman, M. Soumeillant, J. Simpson, B. Zheng, D. Fanfair, M. Mahoney, B. Mudryk, R. J. Fox, Y. Hsaio, S. Murugesan, D. A. Conlon, F. G. Buono and M. D. Eastgate, J. Org. Chem., 2014, 79, 8757-8767.

5 H. Y. Kim and K. Oh, Org. Lett., 2014, 16, 5934-5936.

6 J. Skácel, J. Budka, V. Eigner and P. Lhoták, Tetrahedron, 2015, 71, 1959-1965.

7 G. Sartori and R. Maggi, Advances in Friedel-Crafts acylation reactions: Catalytic and green processes, Taylor \& Francis, Boca Raton, 2010.

8 G. K. S. Prakash, T. Mathew and G. A. Olah, Acc. Chem. Res., 2012, 45, 565-577.

9 A. Perrier, M. Keller, A.-M. Caminade, J.-P. Majoral and A. Ouali, Green Chem., 2013, 15, 2075-2080.

10 H. Ishitani, H. Suzuki, Y. Saito, Y. Yamashita and S. Kobayashi, Eur. J. Org. Chem., 2015, 2015, 5485-5499.

11 M. Mu, L. Chen, Y. Liu, W. Fang and Y. Li, RSC Adv., 2014, 4, 36951-36958.

12 M. Satish Kumar, K. Chinna Rajanna, P. Venkanna and M. Venkateswarlu, Tetrahedron Lett., 2014, 55, 1756-1759.

13 T. J. Williams and M. F. Greaney, Org. Lett., 2014, 16, 40244027.

14 P. H. Tran, P. E. Hansen, H. M. Hoang, D.-K. N. Chau and T. N. Le, Tetrahedron Lett., 2015, 56, 2187-2192.

15 P. H. Tran, P. E. Hansen, H. T. Nguyen and T. N. Le, Tetrahedron Lett., 2015, 56, 612-618.

$16 \mathrm{~J} . \mathrm{Hu}$, E. A. Adogla, Y. Ju, D. Fan and Q. Wang, Chem. Commun., 2012, 48, 11256-11258.

17 Y. Yang, B. Zhou and Y. Li, Adv. Synth. Catal., 2012, 354, 2916-2920.

18 R. J. Wakeham, J. E. Taylor, S. D. Bull, J. A. Morris and J. M. Williams, Org. Lett., 2013, 15, 702-705.

19 H. Luo, L. Pan, X. Xu and Q. Liu, J. Org. Chem., 2015, 80, 8282-8289.

20 P. H. Tran, V. H. Huynh, P. E. Hansen, D.-K. N. Chau and T. N. Le, Asian J. Org. Chem., 2015, 4, 482-486.

21 V. I. Parvulescu and C. Hardacre, Chem. Rev., 2007, 107, 2615-2665.

22 P. Wasserscheid and T. Welton, Ionic Liquids in Synthesis, Wiley-VCH, Weinheim, 2008.

23 J. P. Hallett and T. Welton, Chem. Rev., 2011, 111, 3508-3576.

24 M. A. Martins, C. P. Frizzo, A. Z. Tier, D. N. Moreira, N. Zanatta and H. G. Bonacorso, Chem. Rev., 2014, 114, PR1-PR70.

25 C. Z. Qiao, Y. F. Zhang, J. C. Zhang and C. Y. Li, Appl. Catal., A, 2004, 276, 61-66.
26 H. Xin, Q. Wu, M. Han, D. Wang and Y. Jin, Appl. Catal., A, 2005, 292, 354-361.

27 F. Coleman, G. Srinivasan and M. Swadzba-Kwasny, Angew. Chem., Int. Ed., 2013, 52, 12582-12586.

28 M. J. Earle, U. Hakala, C. Hardacre, J. Karkkainen, B. J. McAuley, D. W. Rooney, K. R. Seddon, J. M. Thompson and K. Wahala, Chem. Commun., 2005, 903-905.

29 C. Li, W. Liu and Z. Zhao, Catal. Commun., 2007, 8, 18341837.

30 J. Estager, J. D. Holbrey and M. Swadzba-Kwasny, Chem. Soc. Rev., 2014, 43, 847-886.

31 H. A. Derbala, J. Heterocycl. Chem., 2012, 49, 700-704.

32 N. V. Plechkova and K. R. Seddon, Chem. Soc. Rev., 2008, 37, 123-150.

33 A. P. Abbott, G. Capper, D. L. Davies, R. K. Rasheed and V. Tambyrajah, Chem. Commun., 2003, 70-71.

34 A. P. Abbott, D. Boothby, G. Capper, D. L. Davies and R. K. Rasheed, J. Am. Chem. Soc., 2004, 126, 9142-9147.

35 S. Tang, G. A. Baker and H. Zhao, Chem. Soc. Rev., 2012, 41, 4030-4066.

36 A. P. Abbott, G. Capper, D. L. Davies, H. L. Munro, R. K. Rasheed and V. Tambyrajah, Chem. Commun., 2001, 2010-2011.

37 C. Ruß and B. König, Green Chem., 2012, 14, 2969-2982.

38 Q. Zhang, K. De Oliveira Vigier, S. Royer and F. Jerome, Chem. Soc. Rev., 2012, 41, 7108-7146.

39 Y. Dai, J. van Spronsen, G. J. Witkamp, R. Verpoorte and Y. H. Choi, Anal. Chim. Acta, 2013, 766, 61-68.

40 A. P. Abbott, R. C. Harris, F. Holyoak, G. Frisch, J. Hartley and G. R. T. Jenkin, Green Chem., 2015, 17, 2172-2179.

41 C. R. Müller, I. Lavandera, V. Gotor-Fernández and P. Domínguez de María, ChemCatChem, 2015, 7, 2654-2659.

42 J. A. Sirviö, M. Visanko and H. Liimatainen, Green Chem., 2015, 17, 3401-3406.

43 H.-C. Hu, Y.-H. Liu, B.-L. Li, Z.-S. Cui and Z.-H. Zhang, RSC $A d v ., 2015$, 5, 7720-7728.

44 P. Liu, J.-W. Hao, L.-P. Mo and Z.-H. Zhang, RSC Adv., 2015, 5, 48675-48704.

45 Q. Wang, X. Yao, Y. Geng, Q. Zhou, X. Lu and S. Zhang, Green Chem., 2015, 17, 2473-2479.

46 N. Guajardo, C. Carlesi and Á. Aracena, ChemCatChem, 2015, 7, 2451-2454.

47 H. Maka, T. Spychaj and J. Adamus, RSC Adv., 2015, 5, 82813-82821.

48 J. Cao, B. Qi, J. Liu, Y. Shang, H. Liu, W. Wang, J. Lv, Z. Chen, H. Zhang and X. Zhou, RSC Adv., 2016, 6, 21612-21616.

49 A. K. Sanap and G. S. Shankarling, RSC Adv., 2014, 4, 3493834943.

50 A. Kumar, R. D. Shukla, D. Yadav and L. P. Gupta, RSC Adv., 2015, 5, 52062-52065.

51 A. Wang, P. Xing, X. Zheng, H. Cao, G. Yang and X. Zheng, RSC Adv., 2015, 5, 59022-59026.

52 X.-D. Tang, Y.-F. Zhang and J.-J. Li, Catal. Commun., 2015, 70, 40-43.

53 S. K. Guchhait, M. Kashyap and H. Kamble, J. Org. Chem., 2011, 76, 4753-4758. 
54 T.-S. Jiang and G.-W. Wang, Org. Lett., 2013, 15, 788-791. 55 Q. Y. Lai, R. S. Liao, S. Y. Wu, J. X. Zhang and X. H. Duan, New J. Chem., 2013, 37, 4069-4076.

56 R. Y. Tang, X. K. Guo, J. N. Xiang and J. H. Li, J. Org. Chem., 2013, 78, 11163-11171.

57 L. Yu, P. Li and L. Wang, Chem. Commun., 2013, 49, 23682370.
58 C. Wang, S. Wang, H. Li, J. Yan, H. Chi, X. Chen and Z. Zhang, Org. Biomol. Chem., 2014, 12, 1721-1724.

59 Q. Xing, P. Li, H. Lv, R. Lang, C. Xia and F. Li, Chem. Commun., 2014, 50, 12181-12184.

60 P. Zhang, T. Xiao, S. Xiong, X. Dong and L. Zhou, Org. Lett., 2014, 16, 3264-3267. 